\title{
The Effect of the Benson Relaxation Technique on the Quality of Sleep and Working Life of Surgical Technologists in Shiraz
}

\author{
Zinat Mohebbi (iD ${ }^{1}$, Maryam Shaygan ${ }^{2,{ }^{*}}$ and Maryam Ghanavati ${ }^{3}$ \\ ${ }^{1}$ Department of Medical-Surgical Nursing, School of Nursing and Midwifery, Shiraz University of Medical Sciences, Shiraz, Iran \\ ${ }^{2}$ Department of Psychiatric Nursing, Community Based Psychiatric Care Research Centre, School of Nursing and Midwifery, Shiraz University of Medical Sciences, Shiraz, Iran \\ ${ }^{3}$ Department of Operating Room Technologist, School of Nursing and Midwifery, Shiraz University of Medical Sciences, Shiraz, Iran \\ "Corresponding author: Community Based Psychiatric Care Research Center, Shiraz University of Medical Sciences, Shiraz, Iran. Email: m2620.shaygan@gmail.com
}

Received 2021 July 11; Revised 2021 October 13; Accepted 2021 November 24.

\begin{abstract}
Background: This study evaluated the effect of the Benson relaxation method on the quality of sleep and working life of surgical technologists.

Methods: This randomized controlled trial was done on 180 surgical technologists who worked in 9 hospitals in Shiraz. Before the beginning of the intervention, participants were randomly assigned to either experimental or control conditions (simple randomization). The experimental group listened to an audiotape of the Benson relaxation technique twenty minutes periods, two times a day for four weeks, while the control group did not receive any intervention at all. The Pittsburgh sleep quality index and Walton quality of working life (QWL) questionnaires were used to measure the sleep quality and working life of surgical technologists, respectively.

Results: Independent $t$-tests indicated that after the intervention, there were significant improvements regarding the total mean scores of quality of sleep (Mean (SD) Intervention = 2.88 (1.36), Mean (SD) Control =15.1 (3.41), P < 0.001), and working life (Mean (SD) Intervention $=133.78(9.22)$, Mean $(\mathrm{SD})$ Control $=62.18(19.68, \mathrm{P}<0.001)$ and their domains in the intervention group compared to the control group.

Conclusions: Our findings are an important contribution to the previous research regarding the Benson relaxation technique as a non-drug, economical method. The current results can help health professionals for determine which psychological techniques are needed to be emphasized for promoting sleep quality and quality of working life in surgical technologists.
\end{abstract}

Keywords: Benson Relaxation, Quality of Sleep, Quality of Working Life, Surgical Technologist

\section{Background}

In Maslow's pyramid, sleep and rest are among the basic physiological needs of humans. Sleep creates conditions to relieve one's daily tiredness, and this leads to physical restoration (1) so that an unfavorable sleep does not lead to adverse effects on one's general health (2). Sleep has two components: quality and quantity. The quality refers to the attainment of deep sleep, which is more important than the quantity of sleep (3).

Workforce and work environment, stress, and irregular sleep hours are among the important factors that can affect sleep quality. As a matter of fact, most shift work nurses suffer from poor sleep quality (4). In fact, nurses are the largest professional group in the healthcare system, and they are particularly involved in rotating schedules. According to the literature, 57\% (4) and 62\% (5) of nurses in Taiwan and Iran suffer from sleep disorders, respectively
(6). Similar to other nurses, surgical technologists in the surgery wards have a heavy workload and inadequate rest time (7), and they frequently experience several stressors that decrease their quality of sleep, working life (8), and hospital productivity (6).

One other factor that may be affected by workforce, work environment, and shift rotation is quality of working life (QWL). It is a new concept which has been used as a construct that relates to the conveniences or inconveniences of the workplace from the employees' point of view (9). Although there is no consensus on the definition of QWL, it is a multidimensional concept that includes the aspects of job satisfaction, job tension, and organizational commitment (10). The QWL influences the nurses' performance as well as the quality of patient care by nurses (11). Therefore, improvements in the QWL of nurses may have beneficial results for employees, hospitals, and patients (11). There is a need to promote effective programs to improve the qual- 
ity of sleep and working life among surgical technologists in the surgical wards.

The Benson relaxation technique, which was introduced by Herbert Benson in the 1970s, is recognized as a non-pharmacological method for reducing occupational stress and anxiety in midwives and nurses $(12,13)$. Also, it has been shown to improve nurses' fatigue (14). However, no evidence has been found regarding the impact of the Benson relaxation technique on sleep quality and QWL in surgical technologists. Considering the importance of sleep quality and QWL among surgical technologists, this study aimed to evaluate the Benson relaxation method's effect on sleep quality and QWL in this group of nurses.

For predicting and hypothesizing the effects of Benson relaxation technique, the conservation of resources (COR) theory was applied (15), in which people want to protect their material and immaterial (eg, time, psychological health, quality of life, etc.) resources. Based on this theory, people avoid situations resulting in the loss of their resources to shelter themselves from future losses. Kröll et al., in their valuable meta-analysis argue that stress management strategies at work help employees in protecting their resources (16). Conservation of resources has a positive relationship with more job satisfaction or improved psychological health (16). In line with COR theory and prior research, it is assumed that Benson relaxation training has a positive impact on sleep quality and QWL in surgical technologists.

\section{Methods}

\subsection{Study Design}

This randomized controlled study with a pretestposttest design (IRCT20100919004775N12), was done to assess the effectiveness of the Benson relaxation method (independent variable) on the working life quality and sleep quality (dependent variables) of surgical technologists who worked as scrub nurse and circular nurses for surgical interventions in the operation rooms of nine hospitals affiliated to Shiraz University of Medical Sciences.

\subsection{Participants}

Our sample consisted of 180 Surgical Technologists with Associate (ASc), Bachelor (BSc), and Master (MSc) degrees. The surgical technologists were selected by the simple sampling method from the operating rooms of nine hospitals affiliated with Shiraz University of Medical Sciences.

\subsection{Inclusion Criteria}

The following criteria were considered: having the required degree (ASc, BSc, or MSc) in surgical technology, willing to participate in the study, not taking any sedative or sleep-inducing medication over the past month $(17,18)$, having a Pittsburgh score of $\geq 5$, as well as a low (35-80) or moderate (81 - 130) score on Walton's quality of working life questionnaire $(19,20)$.

\subsection{Exclusion Criteria}

The following exclusion criteria were also considered: a recent experience of a very stressful event before or throughout the study period, participating in similar programs in the past.

\subsection{Measurement Instruments}

The tools for collecting data had three parts. The first part included questions assessing demographic data such as age, sex, marital status, educational degree, employment status, work experience, number of night shifts, and number of work shifts. The second part was the Pittsburgh sleep quality index questionnaire. The sleep quality (19) as a self-report scale assesses sleep habits and also the respondents' perceived sleep quality providing information regarding seven sleep components (Table 1). Sleep quality is scored from 0 (no difficulty) to 3 (severe difficulty), and its total score is the sum of its seven components ranging from 0 - 21. A score of more than or equal to 5 indicates poor sleep quality, whereas a score of less than 5 indicates good sleep quality. This scale has been widely applied in many investigations (21-25). The Cronbach's alpha of 0.83 and test-retest reliability of 0.85 have been reported for sleep quality (19). A specificity of $86.5 \%$ and a sensitivity of $89.6 \%$ have been revealed for the experimental and control respondents at a cutoff point of 5 (19). The Persian version of sleep quality has been reported with Cronbach's alpha coefficient of 0.77 for 125 patients with psychiatric disorders and 133 healthy individuals (25).

The third section was the quality of work-life questionnaire developed by Walton, which has 35 multiple choice questions that are scored from 1 (completely dissatisfied) to 5 (completely satisfied). It evaluates the quality of eight domains of work-life (Table 2) (20). The minimum and maximum scores were 35 and 175, respectively (scores 35 80: poor QWL, 81 - 130: moderate QWL, 130 - 175: good QWL) (20). Ten faculty members at Kashan University of Medical Sciences confirmed the content validity of the tool. Its reliability was evaluated by some previous researches, and the reliability coefficient was 0.86 - 0.95 (26-28). 
Mohebbi Z et al.

\begin{tabular}{|c|c|c|c|}
\hline Domains & Intervention & Control & P-Value $^{\text {b }}$ \\
\hline \multicolumn{4}{|c|}{ Subjective sleep quality } \\
\hline Before & $1.71 \pm 0.58$ & $1.81 \pm 0.57$ & $0.25(1.17)$ \\
\hline After & $0.58 \pm 0.49$ & $1.90 \pm 0.56$ & $<0.001^{* * *}(16.83)$ \\
\hline Mean change & $-1.12 \pm 0.66$ & $0.08 \pm 0.38$ & $<0.001^{* * *}(14.95)$ \\
\hline P-value ${ }^{c}$ & $<0.001^{* * * *}(-16)$ & $0.25(2)$ & \\
\hline \multicolumn{4}{|l|}{ Sleep latency } \\
\hline Before & $2.04 \pm 0.93$ & $1.92 \pm 1.08$ & $0.43(0.79)$ \\
\hline After & $0.41 \pm 0.44$ & $1.62 \pm 0.97$ & $<0.001^{* * *}(10.77)$ \\
\hline Mean change & $-1.63 \pm 0.89$ & $-0.3 \pm 0.93$ & $<0.001^{* * *}(9.80)$ \\
\hline P-value ${ }^{c}$ & $<0.001^{* * *}(-17.52)$ & $0.32(-3.06)$ & \\
\hline \multicolumn{4}{|l|}{ Sleep duration } \\
\hline Before & $2.28 \pm 0.74$ & $2.28 \pm 0.93$ & $0.89(0.00)$ \\
\hline After & $2.26 \pm 0.74$ & $2.07 \pm 1.04$ & $<0.001(1.41)$ \\
\hline Mean change & $0.94 \pm 0.51$ & $-0.21 \pm 0.06$ & $<0.001^{* * *}(8.91)$ \\
\hline P-value ${ }^{c}$ & $<0.001^{* * *}(0.39)$ & $0.11^{* * *}(0.89)$ & \\
\hline \multicolumn{4}{|c|}{ Habitual sleep efficiency } \\
\hline Before & $3 \pm 0.53$ & $3 \pm 0.48$ & $0.56(0.00)$ \\
\hline After & $0.55 \pm 0.12$ & $3 \pm 0.44$ & $<0.001^{* * *}(50.96)$ \\
\hline Mean change & $-2.45 \pm 0.49$ & 0 & $<0.001^{* * *}(47.43)$ \\
\hline P-value ${ }^{c}$ & $<0.001^{* * *}(-47.38)$ & $0.99(0.00)$ & \\
\hline \multicolumn{4}{|l|}{ Sleep disturbances } \\
\hline Before & $8.66 \pm 3.67$ & $9.05 \pm 4.05$ & $0.50(0.68)$ \\
\hline After & $1.17 \pm 1.06$ & $9.20 \pm 2.95$ & $<0.001^{* * *}(24.30)$ \\
\hline Mean change & $-7.48 \pm 3.48$ & $0.14 \pm 2.50$ & $<0.001^{* * *}(16.87)$ \\
\hline P-value ${ }^{c}$ & $<0.001^{* * *}(-20.21)$ & $0.63(0.54)$ & \\
\hline \multicolumn{4}{|c|}{ Use of sleeping medication } \\
\hline Before & $0.12 \pm 0.39$ & $0.07 \pm 0.26$ & $0.57(1.01)$ \\
\hline After & 0 & $0.01 \pm 0.105$ & $0.32(0.90)$ \\
\hline Mean change & $-0.12 \pm 0.39$ & $-0.06 \pm 0.29$ & $0.44(1.17)$ \\
\hline P-value ${ }^{c}$ & $0.004^{* *}(-2.92)$ & $0.03^{* *}(-1.94)$ & \\
\hline \multicolumn{4}{|l|}{ Daytime dysfunction } \\
\hline Before & $2.81 \pm 1.07$ & $2.90 \pm 0.99$ & $0.56(0.58)$ \\
\hline After & $0.61 \pm 0.59$ & $3.03 \pm 0.77$ & $<0.001^{* * *}(23.67)$ \\
\hline Mean change & $-2.20 \pm 1.13$ & $0.13 \pm 0.76$ & $<0.001^{* * *}(16.23)$ \\
\hline P-value ${ }^{c}$ & $<0.001^{* * *}(-18.48)$ & $0.11(1.63)$ & \\
\hline \multicolumn{4}{|l|}{ Total score } \\
\hline Before & $13.75 \pm 1.27$ & $12.81 \pm 1.54$ & $0.05(4.46)$ \\
\hline After & $2.88 \pm 1.36$ & $15.1 \pm 3.41$ & $<0.001^{* * *}(31.57)$ \\
\hline Mean change & $-10.87 \pm 0.09$ & $2.30 \pm 1.87$ & $<0.001^{* * *}(66.73)$ \\
\hline P-value ${ }^{c}$ & $<0.001^{* * *}(-9.65)$ & $<0.001^{* * *}(11.67)$ & \\
\hline
\end{tabular}

${ }^{\mathrm{a}}$ Values are expressed as mean $\pm \mathrm{SD}$ unless otherwise indicated. ${ }^{*} \mathrm{P}$-value $<0.01,{ }^{* *} \mathrm{P}$-value $<0.05,{ }^{* * *}$ P-value $<0.001$.

${ }^{\mathrm{b}} t$-test: Comparison of between groups

${ }^{c}$ Paired $t$-test: Comparison of within groups 
Table 2. Comparison of the Groups Regarding the Quality of Working Life Before and After the Intervention ${ }^{\text {a }}$

\begin{tabular}{|c|c|c|c|}
\hline Domains & Intervention & Control & P-Value $^{\text {b }}$ \\
\hline \multicolumn{4}{|c|}{ Adequate and fair compensation } \\
\hline Before & $6.91 \pm 0.19$ & $7.46 \pm 2.10$ & $0.06(2.47)$ \\
\hline After & $13.20 \pm 1.96$ & $6.67 \pm 2.26$ & $<0.001^{* * *}(20.71)$ \\
\hline Mean change & $6.28 \pm 3.03$ & $-0.78 \pm 2.26$ & $<0.001^{* * *}(17.49)$ \\
\hline P-value ${ }^{c}$ & $<0.001^{* * *}(19.62)$ & $<0.02^{* *}(-3.12)$ & \\
\hline \multicolumn{4}{|c|}{ Safe and healthy working environment } \\
\hline Before & $9.01 \pm 0.34$ & $11.57 \pm 4.05$ & $0.03^{* *}(5.97)$ \\
\hline After & $22.71 \pm 2.07$ & $10.87 \pm 4.45$ & $<0.001^{* * *}(22.88$ \\
\hline Mean change & $12.28 \pm 4.27$ & $-0.7 \pm 3.74$ & $<0.001^{* * *}(21.69)$ \\
\hline P-value ${ }^{c}$ & $<0.001^{* * *}(27.3)$ & $0.08(-1.79)$ & \\
\hline \multicolumn{4}{|c|}{ Opportunity to develop human capacities } \\
\hline Before & $9.01 \pm 2.95$ & $10.65 \pm 4.24$ & $0.08(3.01)$ \\
\hline After & $19.41 \pm 2.33$ & $9.58 \pm 4.09$ & $<0.001^{* * *}(19.81)$ \\
\hline Mean change & $10.40 \pm 3.14$ & $-1.06 \pm 3.84$ & $<0.001^{* * *}(21.92)$ \\
\hline P-value ${ }^{c}$ & $<0.001^{* * *}(33.5)$ & $0.01 * *(-2.58)$ & \\
\hline \multicolumn{4}{|c|}{ Opportunity for continuous growth and job security } \\
\hline Before & $6.65 \pm 2.35$ & $7.66 \pm 3.11$ & $0.01^{* *}(2.46)$ \\
\hline After & $15.50 \pm 2.01$ & $6.97 \pm 2.89$ & $<0.001^{* * *}(23.02$ \\
\hline Mean change & $8.84 \pm 3.14$ & $-0.68 \pm 3.32$ & $<0.001^{* * *}(19.76)$ \\
\hline P-value ${ }^{c}$ & $<0.001^{* * *}(26.78)$ & $0.06(-1.94)$ & \\
\hline \multicolumn{4}{|c|}{ Social coherence in work organization } \\
\hline Before & $6.36 \pm 2.24$ & $7.60 \pm 3.21$ & $0.08(3.005)$ \\
\hline After & $15.66 \pm 1.68$ & $7.12 \pm 3.10$ & $<0.001^{* * *}(22.97)$ \\
\hline Mean change & $9.30 \pm 3.05$ & $-0.47 \pm 3.13$ & $<0.001^{* * *}(21.21)$ \\
\hline P-value ${ }^{c}$ & $<0.001^{* * *}(29.06)$ & $0.15(-1.42)$ & \\
\hline \multicolumn{4}{|c|}{ Regulations and rule orientation } \\
\hline Before & $6.57 \pm 2.31$ & $7.38 \pm 3.08$ & $0.07(1.99)$ \\
\hline After & $15.62 \pm 1.77$ & $7.14 \pm 3.37$ & $<0.001^{* * *}(21.13)$ \\
\hline Mean change & $9.04 \pm 3.06$ & $-0.24 \pm 2.67$ & $<0.001^{* * *}(21.67)$ \\
\hline P-value ${ }^{c}$ & $<0.001^{* * *}(28.25)$ & $0.38(-0.86)$ & \\
\hline \multicolumn{4}{|c|}{ Work and total life space } \\
\hline Before & $4.54 \pm 1.62$ & $5.04 \pm 2.10$ & $0.07(1.78)$ \\
\hline After & $11.95 \pm 1.37$ & $5.40 \pm 2.21$ & $<0.001^{* * * *}(23.89$ \\
\hline Mean change & $7.41 \pm 2.23$ & $0.35 \pm 2.49$ & $<0.001^{* * * *}(20.03$ \\
\hline P-value ${ }^{c}$ & $<0.001^{* * *}(32.22)$ & $0.18(1.34)$ & \\
\hline \multicolumn{4}{|l|}{ Social dependency } \\
\hline Before & $7.06 \pm 2.29$ & $9.10 \pm 3.84$ & $0.09(4.33)$ \\
\hline After & $19.72 \pm 1.63$ & $8.40 \pm 3.95$ & $<0.001^{* * *}(25.13)$ \\
\hline Mean change & $12.65 \pm 2.95$ & $-0.70 \pm 3.28$ & $<0.001^{* * *}(28.71)$ \\
\hline P-value ${ }^{c}$ & $<0.001^{* * *}(8.54)$ & $0.04^{* *}(-2)$ & \\
\hline \multicolumn{4}{|l|}{ Total score } \\
\hline Before & $57.55 \pm 12.27$ & $66.50 \pm 20.33$ & $0.02 * *(3.58)$ \\
\hline After & $133.78 \pm 9.22$ & $62.18 \pm 19.68$ & $<0.001^{* * *}(31.25)$ \\
\hline Mean change & $76.23 \pm 17.59$ & $-4.31 \pm 12.60$ & $<0.001^{* * *}(35.31)$ \\
\hline P-value ${ }^{c}$ & $<0.001^{* * *}(41.20)$ & $0.02 * *(-3.24)$ & \\
\hline
\end{tabular}

${ }^{\mathrm{a}}$ Values are expressed as mean \pm SD unless otherwise indicated. ${ }^{*} \mathrm{P}$-value $<0.01,{ }^{* *} \mathrm{P}$-value $<0.05,{ }^{* * *} \mathrm{P}$-value $<0.001$.

$\mathrm{b}_{t}$-test: Comparison of between groups

${ }^{\mathrm{c}}$ Paired $t$-test: Comparison of within groups 


\subsection{Randomization}

Before the beginning of the intervention, participants were randomly assigned (simple randomization) to either the intervention or the control conditions by an observer who was not involved in the study using the software Random Allocation (allocation concealment). In this way, the personal code of the participants was given to the randomization software, and the software randomly assigned the participants into two groups.

\subsection{Procedure}

Before starting the study, the surgical technologists were provided with information about the nature and objective of the study. Then, they were asked to complete the questionnaires. The pretest results showed that all the surgical technologists had a poor level of sleep quality and poor or moderate QWL, and therefore, they were qualified for the study. Through random allocation, the subjects were assigned to one of the two groups of Benson relaxation and control group, with 90 surgical technologists in each group. The risk of contamination was minimized by the fact that implementation of the Benson relaxation technique in the intervention group was done after collecting pretest and post-test data of the control group.

According to some previous studies (29), the intervention was carried out twice per day, each time for twenty minutes for four weeks. After the end of the fourth week, the respondents answered the questionnaires again to obtain the post-test scores.

\subsection{Implementation of Benson Relaxation Technique}

Initially, in each hospital, an educational pamphlet was given to the experimental group. The participants of this group were trained in a group session on how to properly perform the Benson relaxation technique, and their questions were answered by a trained surgical technologist (the third author). Then, the audio file of the relaxation technique was shared with each individual on a mobile phone or USB drive. Two days later, an individual training session was held for each participant, in a suitable atmosphere away from noise. Depending on the facilities of the operating room in each hospital, the meeting place was different. During the training sessions, the participants were in very comfortable positions, and music was played to cover the noise that came from outside. The relaxation technique was started while the participant was in a supine or sitting position. The Benson relaxation technique for each patient individually was carried out for 20 minutes. The patient must (1) be in a relaxed sitting position, (2) close his eyes, (3) relax all his muscles beginning at his feet and progressing up to his face followed by relaxing all body parts, (4) respirate through his nose, (5) listen to his breathing sound, (6) say the word "one" or "God" silently to himself while exhaling $(29,30)$, and continue for 20 minutes. Music was played back for 20 minutes, and there was no need to set alarm clocks to indicate the end of the performance. When the music finished, the eyes remained closed for a few minutes, and then they were opened. The participants sat there for a few minutes and then slowly rose. At the end of the training session, participants were given a daily schedule to record their training. It was emphasized that the relaxation training should be done regularly twice per day for four weeks, and the interval between each relaxation training should be 4 to 6 hours. The trained surgical technologist was in touch with the experimental group through text messages and/or phone calls to make sure that they have used the technique properly. After the post-assessment, the interested participants in the control group received the same education from the trained surgical technologist.

\subsection{Statistical Analysis}

Descriptive statistics, such as means \pm SDs for continuous variables and frequency (percentage) for categorical variables were used to characterize the sample. Chi-square tests were utilized to compare categorical variables.

Paired $t$-test was applied for determining the statistically significant differences in questionnaire scores measured before and after the intervention. Comparisons of between-groups differences of sleep quality and QWL scores were assessed using independent $t$-tests. SPSS 22 was used for the statistical analyses.

\subsection{Ethical Considerations}

This research was approved by the Ethics Committee of Shiraz University of Medical Sciences (IR.SUMS.REC.1398.657). Before the study, the importance, aim, and methodology of the study were explained to the subjects, and they completed an informed consent form. We assured them of the confidentiality of the information and their right to withdraw from the research whenever they wanted.

\section{Results}

\subsection{Characteristics of Sample}

There were 90 participants randomized to the intervention group and 90 to the control group $(\mathrm{N}=180)$. The overall mean age of the participants was $31.14 \pm 4.82$ years. Female gender distribution was $65.6 \%$ in the intervention group and $64.4 \%$ in the control group. The percentage of married participants was $58.9 \%$ in the intervention group 
and 53.3\% in the control group. The educational degree of the majority of participants was bachelor in both groups (intervention $=86.7 \%$, control $=84.4 \%$ ). Most participants of both groups worked 1 - 5 night shifts per month (Table 3).

Comparison of groups using chi-square tests and independent $t$-tests revealed no significant differences between the two groups in terms of demographic and occupational characteristics of the participants (P-value $>0.05$, Table 3 ).

\subsection{Improvement in Quality of Sleep}

The results of the independent $t$-tests showed that before the intervention, there were no significant differences between the two groups regarding the mean scores of total sleep quality and its domains (P-values $>0.05$, Table 1 ).

However, after the intervention, there were significant improvements regarding the total mean scores of sleep quality $(t=31.57$, P-value $<0.001)$, sleep latency $(t=10.77$, P-value $<0.001)$, sleep duration $(t=1.41$, P-value $<0.001)$, sleep efficiency $(t=50.96$, P-value $<0.001)$, sleep disturbance $(t=24.30$, P-value $<0.001)$ and daytime dysfunction $(t=23.67$, P-value $<0.001)$ in the intervention group compared to the control group (Table 1, Figure 1).

Also, the results of paired $t$-tests showed that the changes in the total mean scores of sleep quality from before $(13.75 \pm 1.27)$ to after the intervention $(2.88 \pm 1.36)$ were significant in the intervention group (P-value $<0.001$, Table 1). Also, it can be seen in the intervention group that the mean scores of other domains in sleep quality improved significantly after the intervention (P-value $<0.001$, Table 1, Figure 1).

\subsection{Improvement in Quality of Working Life}

The results of independent $t$-tests showed that before the intervention, there were no significant differences between the two groups regarding the mean scores of adequate and fair compensation, opportunity to develop human capacities, social coherence in work organization, regulations and rule orientation, work and total life space, and social dependency (P-values $>0.05$, Table 2). However, the total mean score of quality of working life and domains including safe and healthy working environment, opportunity for continuous growth, and job security before intervention in the intervention group was significantly lesser than the control group $(t=3.58$, P-value $<0.05$, Table 2).

After the intervention, there were significant improvements regarding the overall mean score of quality of working life and its components in the experimental group (133.78 \pm 9.22 ) compared to the control group (62.18 \pm $19.68, t=31.25$, P-value $<0.001$, Table 2, Figure 2 ).
Also, the results of paired $t$-tests showed that the changes in the total mean score of quality of working life from before ( $57.55 \pm 12.27)$ to after the intervention (133.78 \pm 9.22 ) were significant in the intervention group (P-value $<0.001$, Table 2). Also, it was evident in the experimental group that the mean score of other components in quality of working life raised significantly after the intervention (P-value $<0.001$, Table 2, Figure 2).

\section{Discussion}

The objective of the present study was to evaluate the effects of the Benson relaxation technique on the quality of sleep and working life (QWL) of surgical technologists. The results showed that Benson relaxation technique had a significant impact on the sleep quality and QWL scores of the surgical technologists. To our knowledge, it is the first attempt at evaluating the effects of the Benson relaxation technique on the sleep quality and QWL of surgical technologists.

It is well known that many nurses suffer from degrees of poor sleep quality. Based on the results of Silva-Costa, $70.1 \%$ of nurses with rotating shifts had insufficient sleep (31). Also, the results of a recent study showed that the sleep quality of nurses is low in approximately two-thirds of them (32). McDowall found that undertaking shift work was the main predictor of poor sleep quality by adjusting for other variables such as age, sex, and work experience (33).

Our results showed that relaxation training two times per day had a positive impact on the overall sleep quality of the surgical technologists in all dimensions. Consistent with our results, Tahanian et al. showed that progressive muscle relaxation significantly improved the sleep quality and fatigue in emergency nurses (34). Najafi Ghezeljeh also showed that Benson relaxation exercise twice daily for two weeks improved the fatigue of ICU nurses (35). One more recent study demonstrated progressive muscle relaxation as an auxiliary technique to decrease anxiety and increase sleep quality in COVID-19 patients (36). Some other researchers have also claimed that relaxation techniques diminished sleep disturbance $(12,37-41)$ and the use of sleep medication $(39,42,43)$.

Relaxation training can be easily learned; there is no need for a specific time and place, and certain technologies or equipment. According to the research, the reason for the improvement of sleep quality of nurses after relaxation training may be due to the balance between the anterior and posterior hypothalamus responses, which decreases the activity of the sympathetic nervous system (44). Reducing the activity of the sympathetic nervous system 


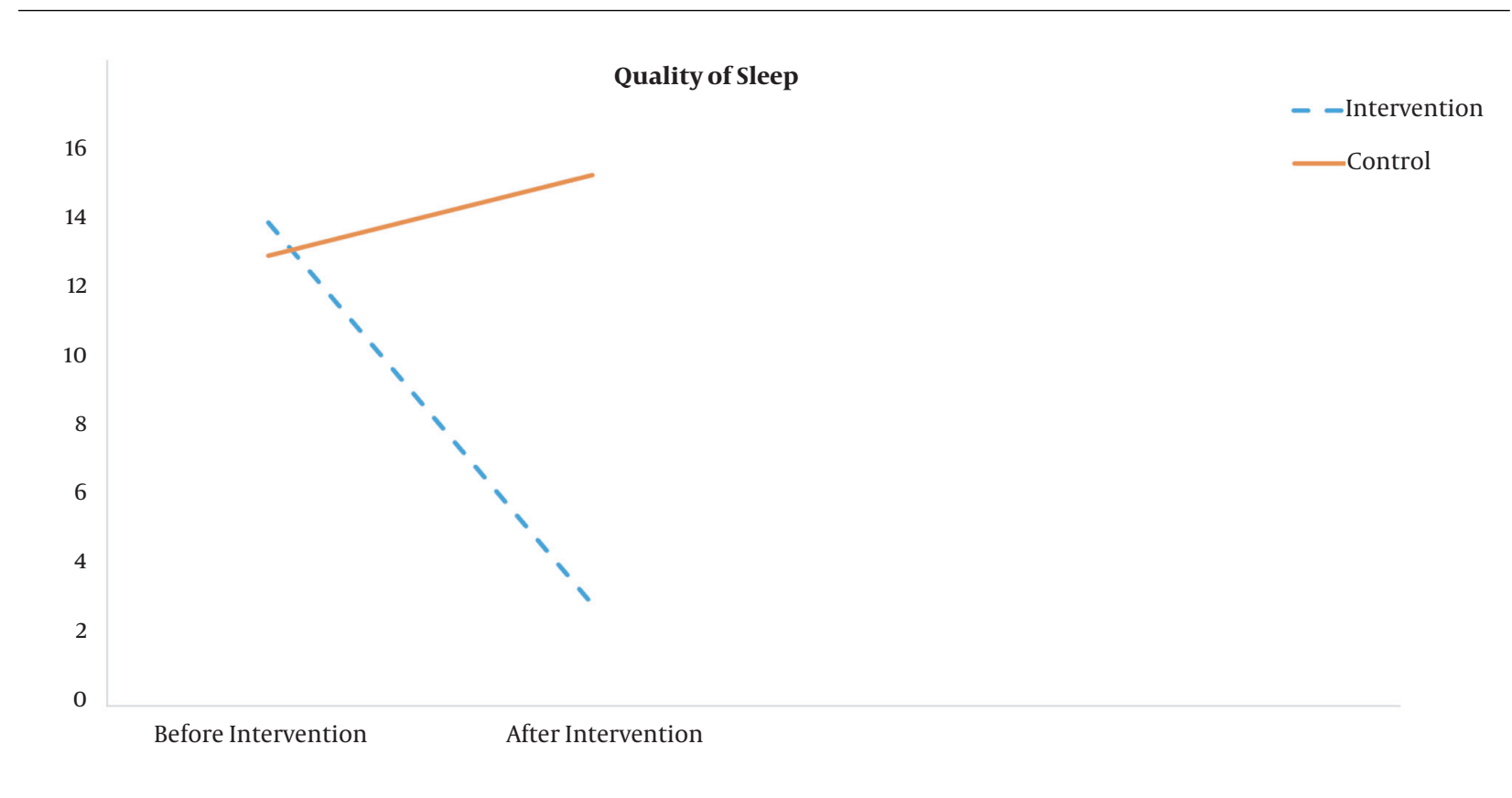

Figure 1. Changes in the total mean scores of quality of sleep before and after intervention

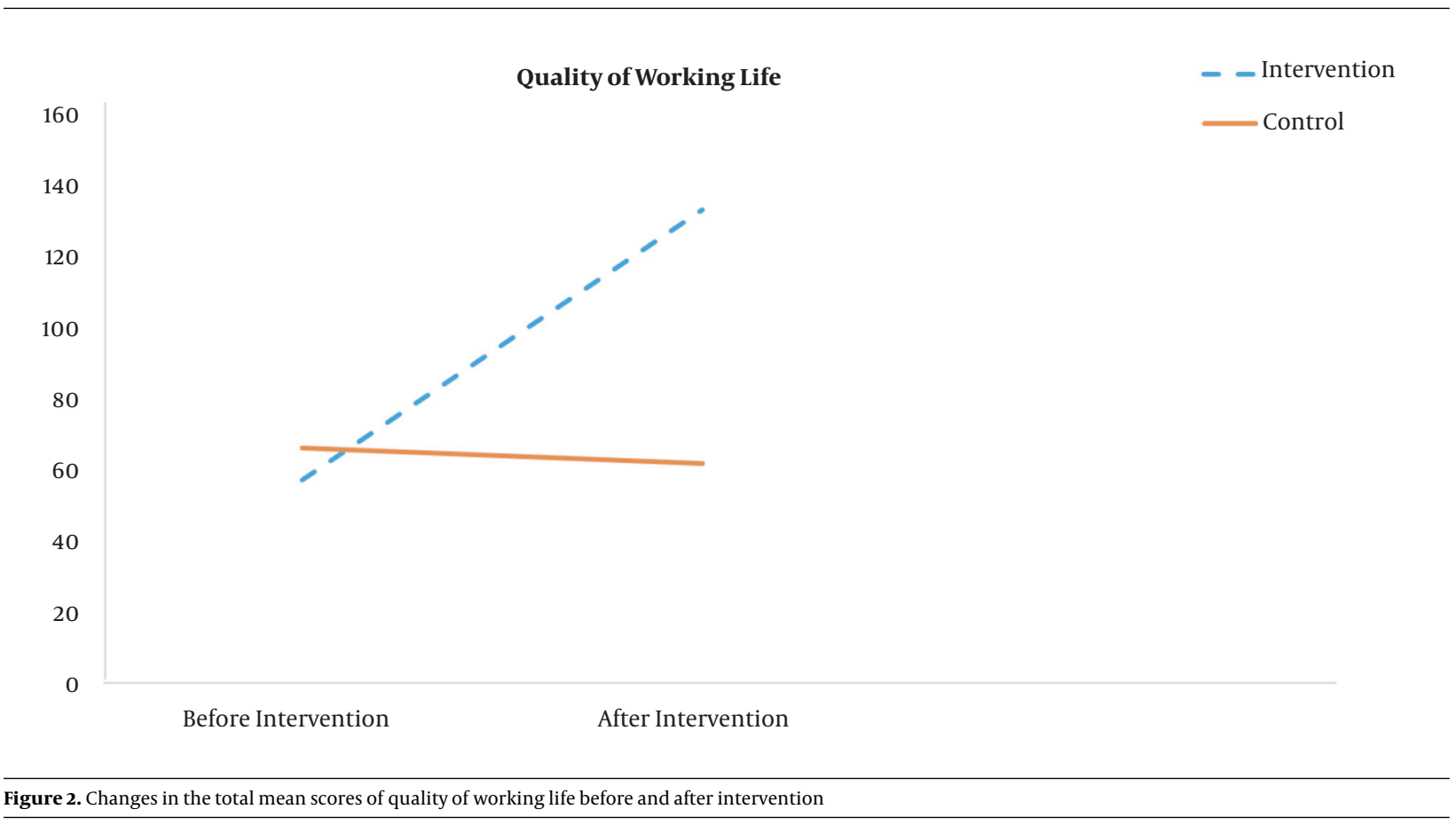




\begin{tabular}{|c|c|c|c|c|}
\hline Variables & Intervention $(\mathrm{N}=90)$ & $\operatorname{Control}(\mathrm{N}=90)$ & $\operatorname{Total}(\mathrm{N}=\mathbf{1 8 0})$ & P-Value $^{b}$ \\
\hline Age $(y)$ & $31.65 \pm 4.85$ & $30.63 \pm 4.79$ & $31.14 \pm 4.82$ & 0.157 \\
\hline Gender & & & & 0.87 \\
\hline Male & $31(34.4)$ & $32(35.6)$ & $63(53)$ & \\
\hline Female & $59(65.6)$ & $58(64.4)$ & $117(65)$ & \\
\hline Marital status & & & & 0.45 \\
\hline Married & $53(58.9)$ & $48(53.3)$ & $101(56.1)$ & \\
\hline Single & $37(41.1)$ & $42(46.7)$ & $79(43.9)$ & \\
\hline Educational degree & & & & 0.58 \\
\hline Bachelor & $78(86.7)$ & $76(84.4)$ & $154(85.6)$ & \\
\hline Undergraduate & $12(13.3)$ & $13(14.4)$ & $25(13.9)$ & \\
\hline Employment status & & & & 0.73 \\
\hline Permanent civil & $40(44.4)$ & $36(40)$ & $76(42.2)$ & \\
\hline Contractual & $14(15.6)$ & $19(21.1)$ & $33(18.3)$ & \\
\hline Quasi-contractual & $1(1.1)$ & $2(2.2)$ & $3(1.7)$ & \\
\hline Corporate & $15(16.7)$ & $11(12.2)$ & $26(14.4)$ & \\
\hline Passing training period & $20(22.2)$ & $22(24.4)$ & $42(23.3)$ & \\
\hline Work experience & & & & 0.50 \\
\hline$<10$ years & $50(55.6)$ & $49(54.4)$ & $99(55)$ & \\
\hline 10 - 20 years & $40(44.4)$ & $41(45.06)$ & $81(45)$ & \\
\hline Night shift & & & & 0.86 \\
\hline $1-5$ & $68(75.6)$ & $78(86.7)$ & $146(80)$ & \\
\hline $6-10$ & $22(23.3)$ & $12(13.3)$ & $34(20)$ & \\
\hline Number of work shifts & & & & 0.60 \\
\hline $1-5$ & $36(40)$ & $35(38.9)$ & $71(39.4)$ & \\
\hline $6-10$ & $36(40)$ & $30(33.3)$ & $66(36.7)$ & \\
\hline $11-15$ & $14(15.6)$ & $21(23.3)$ & $35(19.4)$ & \\
\hline$>15$ & $4(4.4)$ & $4(4.4)$ & $8(4.4)$ & \\
\hline
\end{tabular}

a Values are presented as mean \pm SD or No. (\%).
$\mathrm{b}{ }^{* * \text { P-value }}<0.05$.

reduces heart rate, muscle spasm, body discomfort, levels of stress and anxiety, which may, in turn, improve the sleep quality in nurses $(45,46)$. Moreover, relaxation training increases the nurses' ability to cope with the stressful situation (47), which consequently can protect their resources and improve psychological health and sleep quality among them (16). Consistent with COR theory and prior research, and for the first time, we showed the positive effects of the Benson relaxation training in improving all dimensions of sleep quality in the surgical technologists.

The quality of working life in nurses is highly impaired. A recent study among nurses found that only $4.9 \%$ of them had a good QWL (48). Chegini and colleagues, in their re- cent study, showed that $81.2 \%$ of nurses working in critical care units reported their QWL to be low and 82.8\% reported that their job was highly stressful, and most of them mentioned experiencing high-stress conditions because of organizational policies as well as duty stressors (49). These levels of stress can decrease the QWL of nurses. Based on COR theory, through applying the stress management techniques, employees can obtain knowledge and control, while spending less energy and time against stressful situations. Training relaxation methods are helpful in returning to a state of control and recharging energy levels; thus, further stressful conditions are not taking energy from cases with ever-diminishing sources of energy 
(16). Many studies have shown the effect of stress management on occupational stress and psychological well-being (50). In their meta-analysis, Kröll et al., showed that stress management training is positively related to psychological health, job satisfaction, and performance at work (16). If people can manage their stress, the negative consequences of stress are typically reduced. Reducing stress increases the employee's ability to cope with the stressful situations, which may, in turn, improve the quality of working life. Taken together, these findings provide the first demonstration that Benson relaxation training may improve the quality of working life of surgical technologists. The results highlight that stress management could be a primary target in the improvement of sleep quality and QWL among nurses.

There are some limitations to the present study. One of the limitations of the study was the fact that the participants in the control group were aware of not being subject to any intervention, and this may have affected their answers to the questionnaires. The other limitation is the lack of a long-term follow up to identify the stability of the obtained benefits. Moreover, sleep quality and QWL were assessed only based on the self-report questionnaires, which may be influenced by response bias. Therefore, it would be most valuable if future studies included both self-report and objective measures of sleep quality and QWL. We were also unable to investigate individual differences in the outcome. This is a potential area of future research to investigate individual differences in the treatment response in nurses.

\subsection{Conclusions}

Our findings added to the previous research regarding the Benson relaxation technique as a nonpharmacological, economical method. Our findings support the beneficial effects of the Benson relaxation method on the quality of sleep and working life in surgical technologists. These results are helpful for health professionals in determining which psychological techniques are needed to be emphasized for promoting sleep quality and QWL in surgical technologists.

\section{Footnotes}

Authors' Contribution: Study concept and design: Z. M., M. SH., M. GH; Analysis and interpretation of data: M. SH; Drafting of the manuscript: Z. M., M. SH., M. GH; Critical revision of the manuscript for important intellectual content: M. SH.

\begin{tabular}{|c|c|c|}
\hline Clinical & Trial & Registration \\
\hline
\end{tabular}

Conflict of Interests: The authors have no conflict of interest to declare.

Ethical Approval: This research was approved by the Ethics Committee of Shiraz University of Medical Sciences (IR.SUMS.REC.1398.657).

Funding/Support: This study was supported by Shiraz University of Medical Sciences, Shiraz, Iran (grant number: 98-01-08-19655).

Informed Consent: Before the study, the importance, aim, and methodology of the study were explained to the subjects, and they completed an informed consent form. We assured them of the confidentiality of information and their right to withdraw from the research whenever they want.

\section{References}

1. Steege LM, Dykstra JG. A macroergonomic perspective on fatigue and coping in the hospital nurse work system. Appl Ergon. 2016;54:19-26. doi: 10.1016/j.apergo.2015.11.006. [PubMed: 26851460].

2. Grandner MA. The Cost of Sleep Lost: Implications for Health, Performance, and the Bottom Line. Am J Health Promot. 2018;32(7):1629-34. doi: 10.1177/0890117118790621a. [PubMed: 30099900]. [PubMed Central: PMC6530553].

3. Nordin A, Bjalkebring P. Measuring Counterintuitiveness in Supernatural Agent Dream Imagery. Front Psychol. 2019;10:1728. doi: 10.3389/fpsyg.2019.01728. [PubMed: 31447725]. [PubMed Central: PMC6696895].

4. Rezagholy P, Hannani S, Nasiri Ziba F, Azad NA. Association of Sleep Quality and Quality of Life in the Operating Room Technologists at the Teaching Hospitals Affiliated to Iran University of Medical Sciences. Iran J Nurs. 2019;32(120):26-35. doi: 10.29252/ijn.32.120.26.

5. Shafipour V, Momeni B, Esmaeili R, Yazdani Charati J. The relationship between the quality of work life and sleep in nurses at the intensive care units of teaching hospitals in Mazandaran, Iran. J Nurs Midw Sci. 2016;3(1):28-34. doi:10.18869/acadpub.jnms.3.1.28.

6. Almalki MJ, Fitzgerald G, Clark M. Quality of work life among primary health care nurses in the Jazan region, Saudi Arabia: a crosssectional study. Hum Resour Health. 2012;10:30. doi: 10.1186/1478-449110-30. [PubMed: 22971150]. [PubMed Central: PMC3543175].

7. Phillips N. Berry \& Kohn's operating room technique. Elsevier Health Sciences; 2016.

8. Lajoie P, Aronson KJ, Day A, Tranmer J. A cross-sectional study of shift work, sleep quality and cardiometabolic risk in female hospital employees. BMJ Open. 2015;5(3). e007327. doi: 10.1136/bmjopen-2014007327. [PubMed: 25757950]. [PubMed Central: PMC4360582].

9. Sargent Jr JF. The US science and engineering workforce: Recent, current, and projected employment, wages, and unemployment. Congressional Research Service; 2017.

10. Kahyaoglu Sut H, Mestogullari E. Effect of Premenstrual Syndrome on Work-Related Quality of Life in Turkish Nurses. Saf Health Work. 2016;7(1):78-82. doi: 10.1016/j.shaw.2015.09.001. [PubMed: 27014495]. [PubMed Central: PMC4792910].

11. Abbasi M, Zakerian A, Akbarzade A, Dinarvand N, Ghaljahi M, Poursadeghiyan $\mathrm{M}$, et al. Investigation of the relationship between work ability and work-related quality of life in nurses. Iran J Public Health. 2017;46(10):1404.

12. Jourabchi Z, Satari E, Mafi M, Ranjkesh F. Effects of Benson's relaxation technique on occupational stress in midwives. Nurs- 
ing. 2020;50(9):64-8. doi: 10.1097/01.NURSE.0000694836.00028.28. [PubMed: 32826681].

13. Sajadi M, Goudarzi K, Khosravi S, Farmahini-Farahani M, Mohammadbeig A. Benson's relaxation effect in comparing to systematic desensitization on anxiety of female nurses: A randomized clinical trial. Indian J Med Paediatr Oncol. 2017;38(2):111.

14. Najafi Ghezeljeh T, Sedghian H, Mohaddes Ardabili F, Rezaei Loieh H. Effect of Benson Relaxation on Fatigue of Nurses Working in Intensive Care Units. J Client-Centered Nurs Care. 2015;1(4):211-7. doi: 10.15412/j.Jccnc.04010407.

15. Zisopoulos G, Roussi P, Mouloudi E. Psychological morbidity a year after treatment in intensive care unit. Health Psychol Res. 2020;8(3):8852. doi: 10.4081/hpr.2020.8852. [PubMed: 33553785]. [PubMed Central: PMC7859955].

16. Kröll C, Doebler P, Nüesch S. Meta-analytic evidence of the effectiveness of stress management at work. Eur J Work Organ Psychol. 2017;26(5):677-93. doi: 10.1080/1359432x.2017.1347157.

17. Moradi T, Maghaminejad F, Azizi-Fini I. Quality of Working Life of Nurses and its Related Factors. Nurs Midw Stud. 2014;3(2). doi: 10.17795/nmsjournal19450.

18. Kamkar M, Salimi Z, Ghorbani Koohi Kheili S, Shahini N. The relationship between quality of sleep and quality of life in nurses. J Fundam Mental Health. 2021;23(2):125-34.

19. Park BK. The Pittsburg Sleep Quality Index (PSQI) and Associated Factors in Middle-school Students: A Cross-sectional Study. Child Health Nurs Res. 2020;26(1):55-63. doi:10.4094/chnr.2020.26.1.55.

20. Kitsios F, Kamariotou M. Job satisfaction behind motivation: An empirical study in public health workers. Heliyon. 2021;7(4):1-8. doi: 10.1016/j.heliyon.2021.e06857. [PubMed: 33981905]. [PubMed Central: PMC8085703].

21. Ahmadinezhad M, Kargar M, Vizeshfar F, Hadianfard MJ. Comparison of the Effect of Acupressure and Pilates-Based Exercises on Sleep Quality of Postmenopausal Women: A Randomized Controlled Trial. Iran J Nurs Midwifery Res. 2017;22(2):140-6. doi: 10.4103/1735-9066.205954. [PubMed: 28584553]. [PubMed Central: PMC5442996].

22. Chang WP, Chang YP. Meta-Analysis of Changes in Sleep Quality of Women with Breast Cancer before and after Therapy. Breast Care (Basel). 2020;15(3):227-35. doi: 10.1159/000502943. [PubMed: 32774216]. [PubMed Central: PMC7383255].

23. Chehri A, Nourozi M, Eskandari S, Khazaie H, Hemati N, Jalali A. Validation of the Persian version of the Pittsburgh Sleep Quality Index in elderly population. Sleep Sci. 2020;13(2):119.

24. Chen MC, Liu HE, Huang HY, Chiou AF. The effect of a simple traditional exercise programme (Baduanjin exercise) on sleep quality of older adults: a randomized controlled trial. Int J Nurs Stud. 2012;49(3):265-73. doi: 10.1016/j.ijnurstu.2011.09.009. [PubMed: 21963235].

25. Farrahi Moghaddam J, Nakhaee N, Sheibani V, Garrusi B, Amirkafi A. Reliability and validity of the Persian version of the Pittsburgh Sleep Quality Index (PSQI-P). Sleep Breath. 2012;16(1):79-82. doi: 10.1007/s11325-010-0478-5. [PubMed: 21614577].

26. Rahbar A, Nasiripour AA, Mahmoodi-Majdabadi M. Structural Equation Modeling to Explore the Relationship Between Organizational Culture Dimensions and Implementation of Knowledge Management in Teaching Hospitals. Health Scope. 2020;9(2). doi: 10.5812/jhealthscope.96868

27. Dargahi H, Changizi V, Jazayeri Gharabagh E. Radiology Employees' Quality of Work Life. Acta Medica Iranica. 2012:250-6.

28. Nazari A, Alimohammadzadeh K, Hosseini SM. A study of relationship Quality of Working Life and its relation with the productivity of nurses in hospitals in Qom: 2016.J Res Dev Nurs Midw. 2019;16(1):25-32. doi:10.29252/jgbfnm.16.1.26.

29. Heshmati Far N, Salari M, Rakhshani MH, Borzoee F, Sahebkar M. The effects of Benson relaxation technique on activities of daily living in hemodialysis patients; A single-blind, randomized, parallel-group, controlled trial study. Complement Ther Clin Pract. 2020;39:101133. doi: 10.1016/j.ctcp.2020.101133. [PubMed: 32379668].

30. Daneshpajooh L, Najafi Ghezeljeh T, Haghani H. Comparison of the effects of inhalation aromatherapy using Damask Rose aroma and the Benson relaxation technique in burn patients: A randomized clinical trial. Burns. 2019;45(5):1205-14. doi: 10.1016/j.burns.2019.03.001. [PubMed: 30948278].

31. Silva-Costa A, Griep RH, Rotenberg L. Associations of a Short Sleep Duration, Insufficient Sleep, and Insomnia with SelfRated Health among Nurses. PLoS One. 2015;10(5). e0126844. doi: 10.1371/journal.pone.0126844. [PubMed: 25961874]. [PubMed Central: PMC4427441].

32. Tarhan M, Aydın A, Ersoy E, Dalar L. The sleep quality of nurses and its influencing factors. Eurasian J Pulmonol. 2018;20(2):78-84.

33. McDowall K, Murphy E, Anderson K. The impact of shift work on sleep quality among nurses. Occup Med (Lond). 2017;67(8):621-5. doi: 10.1093/occmed/kqx152. [PubMed: 29040745].

34. Tahanian M, Jouybari L, Vakil MA, Sanagoo A, Haghdust Z. The Effect of Progressive Muscle Relaxation on Sleep Quality and Fatigue among Pre-Hospital Emergency Staff in the Center of Management of Accident and Medical Emergency in Golestan Province. Iran Occupational Health. 2018;15(2):101-10.

35. Najafi Ghezeljeh T. Investigating the effect of listening to nature sounds on sleep quality in patients hospitalized in cardiac care units. Complement Med J. 2018;8(1):2167-80.

36. Liu K, Chen Y, Wu D, Lin R, Wang Z, Pan L. Effects of progressive muscle relaxation on anxiety and sleep quality in patients with COVID-19. Complement Ther Clin Pract. 2020;39:101132. doi: 10.1016/j.ctcp.2020.101132. [PubMed: 32379667]. [PubMed Central: PMC7102525].

37. Hossini A, Azimian J, Motalebi SA, Mohammadi F. The effect of holy quran recitation on the quality of sleep among older people residing in nursing homes. Iran J Ageing. 2019;14(2):236-47.

38. Arab Z, Shariati AR, Asayesh H, Vakili MA, Bahrami-Taghanaki H, Azizi H. A sham-controlled trial of acupressure on the quality of sleep and life in haemodialysis patients. Acupunct Med. 2016;34(1). doi: 10.1136/acupmed-2014-010369. [PubMed: 26215770].

39. Mirhosseini S, Rezaei M, Mirbagher Ajorpaz N. The Effect of Benson Relaxation Technique on General Health of Patients with Multiple Sclerosis: A Randomized Controlled Trial. J Res Dev Nurs Midw. 2021;18(1):17-20.

40. Moradi Mohammadi F, Bagheri H, Khosravi A, Ameri M, Khajeh M M. The Effect of Benson Relaxation Technique on Sleep Quality after Coronary Artery Bypass Graft Surgery. Avicenna J Nurs Midwifery Care. 2020;27(6):371-80. doi:10.30699/ajnmc.27.6.371.

41. Farzana M, Kumar M. Effect of Jacobson's Progressive Relaxation Technique Over Sleep Disturbances and Quality of Life in Chronic Rheumatoid Arthritis. Indian J Public Health Res Dev. 2020;11(2). doi: 10.37506/v11/i2/2020/ijphrd/194763.

42. Bahceli A, Karabulut N. The Effects of Progressive Relaxation Exercises following Lumbar Surgery: A Randomized Controlled Trial. Complement Med Res. 2021;28(2):114-22. doi: 10.1159/000509055. [PubMed: 32882693].

43. Tang SK, Tse MMY, Leung SF, Fotis T. The effectiveness, suitability, and sustainability of non-pharmacological methods of managing pain in community-dwelling older adults: a systematic review. BMC Public Health. 2019;19(1):1488. doi: 10.1186/s12889-019-7831-9. [PubMed: 31703654]. [PubMed Central: PMC6842175].

44. Ferendiuk E, Biegańska JM, Kazana P, Pihut M. Progressive muscle relaxation according to Jacobson in treatment of the patients with temporomandibular joint disorders. Folia Medica Cracoviensia. 2019;59(3):113-22.

45. Khajeh Hosseini S, Sayadi A, Mobini Lotfabad M, Heidari S. The effect of Benson's relaxation technique on sleep quality among shiftworking nurses in hospitals. Hayat. 2020;25(4 b001111).

46. Pelit-Aksu S, Ozkan-Sat S, Yaman-Sozbi RS, Senturk-Erenel A. Effect of 
progressive muscle relaxation exercise on clinical stress and burnout in student nurse interns. Perspect Psychiatr Care. 2021;57(3):1095-102. doi: 10.1111/ppc.12662. [PubMed: 33103776].

47. Keyhani A, Rasuli Azad M, Moghadasi AN, Omidi A. The effect of acceptance and commitment therapy on cognitive fusion, symptoms of anxiety, and quality of life in the female patients with Multiple Sclerosis. Feyz J Kashan Univ Med Sci. 2019;23(4):380-8.

48. Mohammadi M, Mozaffari N, Dadkhah B, Etebari Asl F, Etebari Asl Z Study of work-related quality of life of nurses in Ardabil Province Hos- pitals. J Health Care. 2017;19(3):108-16.

49. Chegini Z, Asghari Jafarabadi M, Kakemam E. Occupational stress, quality of working life and turnover intention amongst nurses. Nurs Crit Care. 2019;24(5):283-9. doi: 10.1111/nicc.12419. [PubMed: 30873678].

50. Karimyar Jahromi M, Minaei S, Abdollahifard S, Maddahfar M. The Effect of Stress Management on Occupational Stress and Satisfaction among Midwives in Obstetrics and Gynecology Hospital Wards in Iran. Glob J Health Sci. 2016;8(9):91. doi: 10.5539/gjhs.v8n9p91. [PubMed: 27157171]. [PubMed Central: PMC5064068]. 